\title{
Reactive Oxygen Species-Induced Expression of B cell Activating Factor (BAFF) Is Independent of Toll-like Receptor 4 and Myeloid Differentiation Primary Response Gene 88
}

\author{
Hyun-Sun KIm, and Eun-Yi MooN* \\ Department of Bioscience and Biotechnology, Sejong University, Seoul 143-747, Republic of Korea
}

(Received February 23, 2009; Revised March 20, 2009; Accepted April 13, 2009)

\begin{abstract}
Reactive oxygen species play a role in signal transduction and in many human diseases. B-cell activating factor (BAFF) plays a role for mature B cell generation and maintenance and for the incidence of autoimmune diseases. We previously reported that BAFF expression was induced by ROS. In this study, we investigated whether ROS-induced BAFF expression was affected by toll-like receptor (TLR) 4 or myeloid differentiation primary response gene $(\mathrm{MyD}) 88$. BAFF expression was increased by serum deprivation that is an experimental modification to produce ROS. In contrast, TLR4 and MyD88 were decreased by serum deprivation. Although ROS production was decreased in TLR4-nonfunctional or MyD88-deficient splenocytes as compared to that in control mice, serum deprivation increased ROS production and augmented BAFF expression in both cells. $50 \mu \mathrm{M} \mathrm{H}_{2} \mathrm{O}_{2}$ also increased BAFF expression in TLR4-deficient or MyD88-deficient splenocytes. Collectively, results show that BAFF expression may be mediated by TLR4 or MyD88independent manner and TLR4 or MyD88 may not be required in BAFF expression.
\end{abstract}

Keywords: BAFF, TLR4, MyD88, ROS

\section{INTRODUCTION}

Mature $B$ cell generation and maintenance are regulated by B-cell activating factor (BAFF). BAFF is produced by macrophages or dendritic cells (DCs) upon stimulation with lipopolysaccharide (LPS) or interferon- $\gamma$. BAFF belongs to the tumor necrosis factor (TNF) family. Its biological role is mediated by the specific receptors, B-cell maturation antigen (BCMA), transmembrane activator and calcium modulator and cyclophilin ligand interactor (TACl) and BAFF receptor (BAFF-R) (Mackay et al., 2003). BAFFdeficient mice exhibit an almost complete loss of follicular and marginal-zone B lymphocytes (Schiemann et al., 2001). BAFF is associated with autoimmune disorders and induces rheumatic arthritis in a transgenic mouse model (Mackay et al., 1999; Schneider et al., 1999). These disorders are well-known Th1-mediated inflammatory diseases. In addition, BAFF induces class-switch DNA recombination to produce IgG, IgA and IgE (Litinskiy et al., 2002),

${ }^{*}$ Corresponding author

Tel: +82-2-3408-3768 Fax: +82-2-466-8768

E-mail: eunyimoon@sejong.ac.kr which is in relation to Th2-mediated immune reactionmediated allergic disorder such as asthma (Rackeman, 1947; Ostergaard, 1985; Corrigan, 2004).

Previously, our reports have shown that BAFF expression was increased by ROS treatment and Prx II gene deletion (Moon et al., 2006) and it was differentially regulated from TLR4 by Prx II (Moon et al., 2008). Peroxiredoxins (Prxs) play a role in ROS degradation. ROS production increased in Prx $\mathrm{II}^{-1-}$ mice compared to wild type mice (Moon et al., 2004; Han et al., 2005; Han et al., 2006; Moon et al., 2006). Toll-like receptors (TLRs) play an important role in the detection of invading pathogens within the body and the subsequent immune response. Among TLRs (Akira et al., 2003), TLR4 agonist, LPS induced ROS generation and ROS are involved in TLR4-associated activation of NF-kB (Sanlioglu et al., 2001; Asehnoune et al., 2004). ROS that produced by LPS-stimulation or Prx II gene deletion, augments BAFF expression through NF- $\mathrm{kB}$ activation (Moon et al., 2006). However, little has been known about the requirement of TLR4 in the regulation of ROS-mediated BAFF expression.

TLR recruits the IL-1R-associated kinase (IRAK) via the adapter MyD88, ultimately leading to the activation of 
NF-kB (Muzio et al., 1997; Wesche et al., 1997). MyD88 was originally isolated as a myeloid differentiation primary response gene that is rapidly induced upon IL-6-stimulated differentiation of M1 myeloleukaemic cells into macrophages (Lord et al., 1990). The C-terminal domain of MyD88 is highly homologous with the cytoplasmic regions of the IL-1 receptor family (Hultmark, 1994) and its N-terminus contains a death domain. Unlike the IL-1 receptor family, MyD88 does not contain a transmembrane portion (Muzio et al., 1997; Wesche et al., 1997). However, little has been known about the requirement of MyD88 in the regulation of ROS-mediated BAFF expression.

In this study, we investigated the role of TLR4 or MyD88 on ROS-mediated BAFF expression. Here, we found that BAFF expression was independent of TLR 4 and MyD88 in ROS-producing cells that were experimentally modified by serum deprivation (Moon, 2008). It suggests that BAFF expression might be mainly regulated by ROS in immune cells.

\section{MATERIALS AND METHODS}

\section{Mice and reagents}

$\mathrm{C} 3 \mathrm{H} / \mathrm{HeN}$ and $\mathrm{C} 3 \mathrm{H} / \mathrm{HeJ}$ mice were purchased from Jackson Laboratory, Japan. Wildtype and MyD88 ${ }^{-1-}$ C57BL/6 mice were obtained by breeding male MyD88 ${ }^{+/-}$and female MyD88 ${ }^{+/-}$mice and by performing the genotyping of animals as described (Adachi et al., 1998). Animals were maintained in the pathogen-free authorized facility in Sejong University where the temperature at $20-22^{\circ} \mathrm{C}$, the humidity $50-60 \%$. The dark/light cycles were 12 hour. All animal procedures were conducted in accordance with the guidelines of the institutional Animal Care and Use Committee, Sejong University. Rabbit anti-mouse TLR4 antibodies were purchased from Sigma-Aldrich (St. Louis, MO). Except where indicated, all other materials are obtained from the Sigma-Aldrich (St. Louis, MO).

\section{Cell preparation}

Spleens were dissected from each mouse in RPMI 1640 supplemented $2 \%$ fetal calf serum (FCS). Splenocytes were obtained by teasing spleen gently with plunger of $3 \mathrm{ml}$ syringe and by sieving through $70 \mu \mathrm{m}$ cell strainer (Falcon, Bedford, MA). Red blood cells were removed by incubating with RBC lysis buffer (Sigma Chemical Co., St. Louis, MO) for 5 minutes. Spleen cells were washed twice with RPMI 1640 medium. Cell numbers were adjusted to appropriate concentrations.

\section{Flow cytometric analyses}

To analyze intracellular amount of ROS, splenocytes $\left(1-10 \times 10^{5}\right)$ were stained with fluorescence dye, DCF-DA (Molecular Probe, Eugene, OR) for 30 minute. Then, 10,000 cells were acquired to analyze intracellular amount of ROS by CELLQuest ${ }^{\mathrm{TM}}$ software in FACScalibur ${ }^{\mathrm{TM}}$ (Becton Dickinson, Franklin Lakes, NJ).

\section{RT-PCR}

RNA was isolated from cells using TRIzol (Invitrogen Life Technology, Carlsbad, CA). cDNA was synthesized from $1 \mu \mathrm{g}$ of total RNA, using oligo (dT) ${ }_{15}$ primers and superscript reverse transcriptase in a final volume of $21 \mu \mathrm{l}$ (Bioneer, Taejeon, Korea). For standard PCR, one $\mu \mathrm{l}$ of the first strand CDNA product was then used as a template for PCR amplification with Taq DNA polymerase (Bioneer, Taejeon, Korea). PCR amplification proceeded as follows: 28 thermocycles of $94^{\circ} \mathrm{C}$ for 30 second, $55^{\circ} \mathrm{C}$ for $30 \mathrm{sec}-$ onds, and $72^{\circ} \mathrm{C}$ for 30 seconds, using oligonucleotides specific for MyD88 (forward: atg acc ccc tag gac aaa cg, reverse: ctt tac cag ctc att tct cac c), glyceraldehyde-3phosphate dehydrogenase (GAPDH) (forward: tcc acc acc ctg ttg ctg ta; reverse: acc aca gtc cat gcc atc ac) and mBAFF (forward: gct ttc cag gga cca gag gaa a; reverse: tta cag cag ttt tag ggc acc aa).

\section{Real- time quantitative RT-PCR}

Real-time PCR for TLR4 was performed using $\mathrm{iQ}^{\mathrm{TM}}$ SYBR $^{\circledR}$ Green Supermix (Bio-Rad Laboratories, Inc., Hercules, CA, USA) and primers used in RT-PCR. For MyD88 amplification, samples were heated to $94^{\circ} \mathrm{C}$ for 8 min and cycled 45 times at $94^{\circ} \mathrm{C}$ for $30 \mathrm{~s}, 56^{\circ} \mathrm{C}$ for $30 \mathrm{~s}$, and $72^{\circ} \mathrm{C}$ for $45 \mathrm{~s}$. iCycler $\mathrm{QQ}^{\mathrm{TM}}{ }^{\mathrm{C}}$ Real-time PCR for mBAFF was performed using TaqMan ${ }^{\circledR}$ Universal PCR Master mix $(2 X)$ and primers (forward: cgc cga cta tac gaa aag gaa ctt a; reverse: ctc ctc caa ggc att tcc tct tt) and FAM ${ }^{\mathrm{TM}}$ dye-labeled TaqMan ${ }^{\circledR}$ MGB probe (cca tgg ctt ctc agc ttt). For mBAFF amplification, samples were heated to $95^{\circ} \mathrm{C}$ for 10 min and cycled 40 times at $95^{\circ} \mathrm{C}$ for $15 \mathrm{~s}$ and $60^{\circ} \mathrm{C}$ for 1 min. Real-time PCR analysis for MyD88 and MBAFF was carried out in duplicate using real-time PCR Detection System from Bio-Rad Laboratories, Inc. (Hercules, CA, USA) and Applied Biosystems (Foster City, CA, USA), respectively. The amount of MyD88 and mBAFF mRNA was determined and normalized by the amount of GAPDH mRNA as an internal control.

\section{Western blot analysis}

Cells were lysed in ice-cold lysis buffer, containing $0.5 \%$ Nonidet P-40 (vol/vol) in 20 mM Tris- $\mathrm{HCl}$ (pH 8.3); 150 mM 
$\mathrm{NaCl}$; protease inhibitors $(2 \mu \mathrm{g} / \mathrm{ml}$ aprotinin, pepstatin, and chymostatin; $1 \mu \mathrm{g} / \mathrm{ml}$ leupeptin and pepstatin; $1 \mathrm{mM}$ PMSF; and $1 \mathrm{mM} \mathrm{Na} \mathrm{VO}_{3}$. Lysates were incubated for 30 minutes on ice prior to centrifugation at $14,000 \mathrm{rpm}$ for 5 minute at $4^{\circ} \mathrm{C}$. Proteins in the supernatant were denatured by boiling for 5 minute in sodium dodecyl sulfate (SDS) sample buffer. Proteins were separated by $12 \%$ SDS-polyacrylamide gel electrophoresis (SDS-PAGE), and then transferred to nitrocellulose membranes. Following this transfer, equal loading of protein was verified by Ponceau staining. The membranes were blocked with $5 \%$ skim milk in Tris-buffered saline with Tween 20 (TBST) (10 mM Tris- $\mathrm{HCl}, \mathrm{pH} 7.6 ; 150 \mathrm{mM} \mathrm{NaCl} ; 0.5 \%$ Tween 20), then incubated with anti-TLR4 antibodies. Bound antibodies were visualized with HRP-conjugated secondary antibodies with the use of enhanced chemiluminescence (ECL) (Pierce, Rockford, IL).

\section{Statistical analyses}

Experimental differences were tested for statistical significance using ANOVA and Students' t-test. $p$ value of $<$ 0.05 or 0.01 was considered to be significant.

\section{RESULTS}

\section{Serum deprivation changed BAFF, MyD88 gene and TLR protein expression}

Given that higher basal level of ROS is one of the mech-

A.

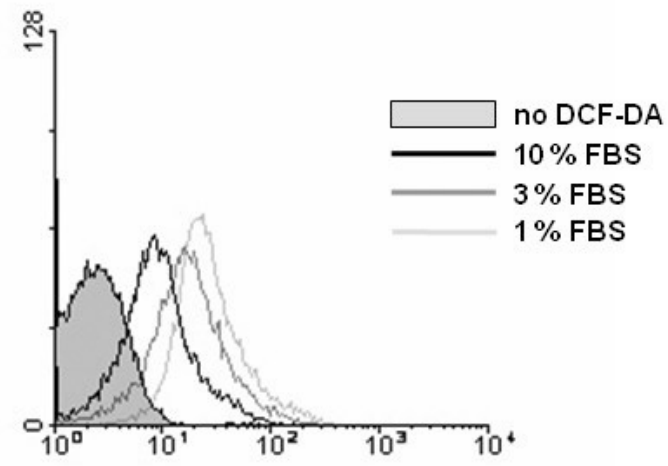

B.

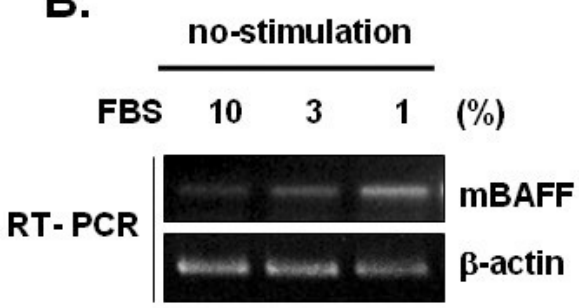

D.

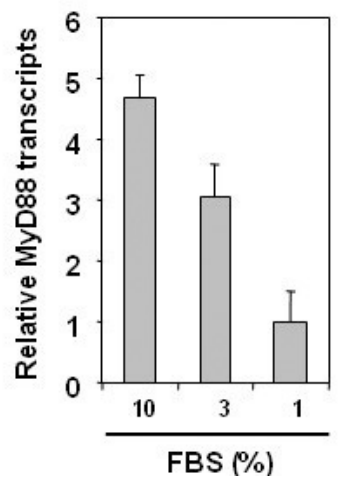

C.

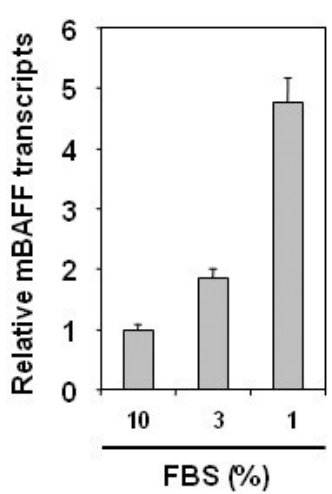

E.

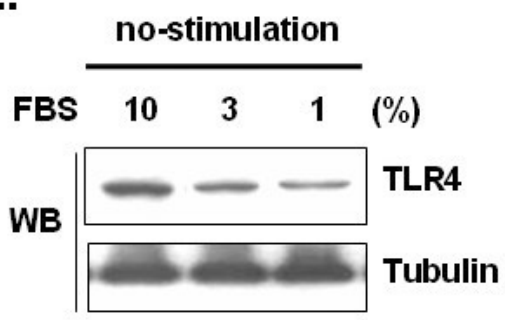

Fig. 1. Reciprocal expression of BAFF transcripts to TLR4 proteins and MyD88 transcripts by serum deprivation. (A) Splenocytes from wild type mice were cultured in the presence of 1, 3 and $10 \%$ FBS. ROS production was measured by the incubation with DCF-DA. 10,000 ROS-positive cells were analyzed by flow cytometry. These data are representative of results obtained with three independent experiments. (B) BAFF transcripts were detected by RT- PCR. (C) and (D) Relative BAFF and MyD88 transcripts in splenocytes cultured with 1 or $3 \%$ FBS to splenocytes with $10 \%$ FBS were measured by real-time quantitative RT-PCR analysis described in materials and methods. Data in bar graph represent mean \pm SED. ${ }^{*} p<0.05$; Significantly different from control cultured with $10 \%$ FBS. (E) TLR4 proteins were detected by Western blot analysis. 
anisms determining intracellular signalings (Choi et al., 2005), we investigated the molecular expression of BAFF, MyD88 gene and TLR protein in the cultures with serum deprivation. When splenocytes were cultured with 1, 3, and $10 \%$ FBS, ROS production was increased as judged by the increase of DCF-DA-responsive cells (Fig. 1A). When BAFF transcripts were detected by RT-PCR and real-time PCR, they were augmented by decreaseing the percentage of FBS (Fig. 1B and C). In contrast, MyD88 transcripts and TLR4 protein levesl were reduced by 1 and $3 \%$ FBS compared to $10 \%$ FBS (Fig. 1D and E). These data suggest that serum deprivation-induced BAFF expression could be independent of TLR4 and MyD88.

\section{ROS-induced BAFF expression was TLR4-independent}

To investigate TLR4-independent BAFF expression, we compared BAFF expression in splenocytes from $\mathrm{C} 3 \mathrm{H} / \mathrm{HeN}$, TLR4 functional and $\mathrm{C} 3 \mathrm{H} / \mathrm{HeJ}$, TLR4 non-functional mice. Intracellular ROS amounts in $\mathrm{C} 3 \mathrm{H} / \mathrm{HeN}$ were higher than that in $\mathrm{C} 3 \mathrm{H} / \mathrm{HeJ}$ (Fig. 2A). BAFF transcripts were in-
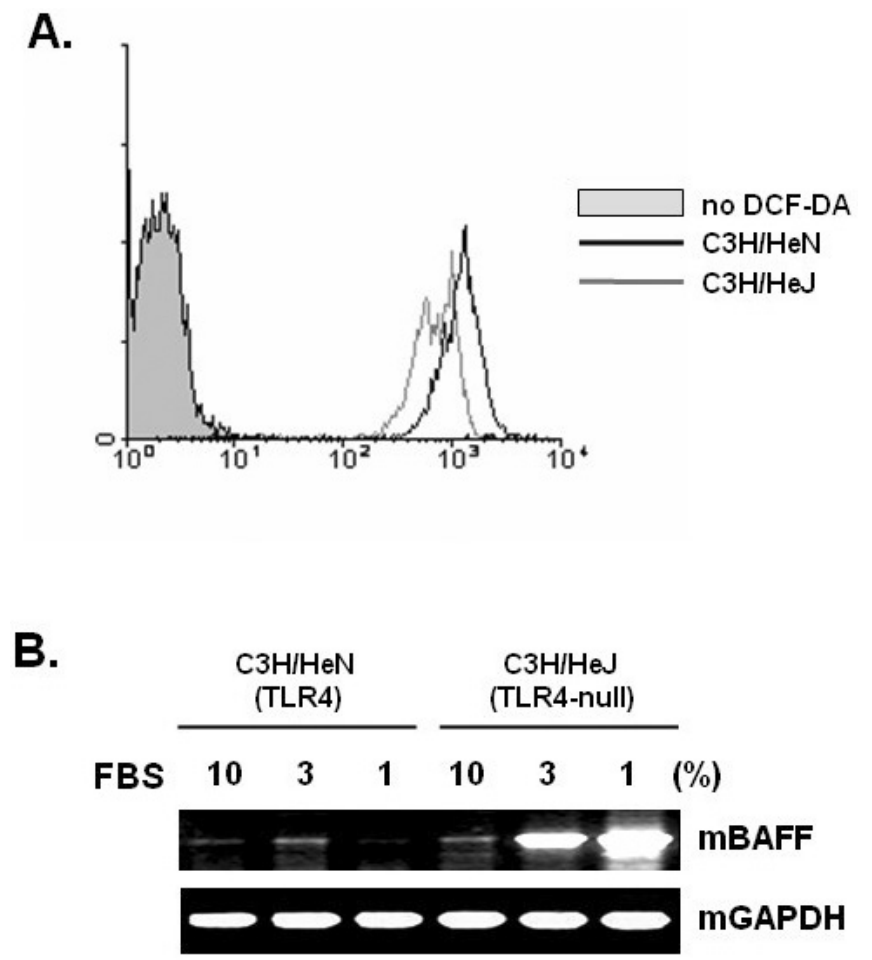

Fig. 2. TLR4-independent BAFF expression in splenocytes. (A) Splenocytes from $\mathrm{C} 3 \mathrm{H} / \mathrm{HeN}$ TLR4-functional and $\mathrm{C} 3 \mathrm{H} / \mathrm{HeJ}$ TLR4-nonfunctional mice were prepared. Intracellular ROS amounts were was measured by the incubation with DCF-DA. 10,000 ROS-positive cells were analyzed by flow cytometry. (B) Splenocytes were cultured in the presence of 1,3 and $10 \%$ FBS. BAFF transcripts were detected by RT-PCR. creased by the incubation with 1, or $3 \%$ FBS compared to $10 \%$ FBS in $\mathrm{C} 3 \mathrm{H} / \mathrm{HeN}$ and $\mathrm{C} 3 \mathrm{H} / \mathrm{HeJ}$ mouse splenocytes. When both types of splenocytes were cultured with 1 or $3 \% \mathrm{FBS}$, BAFF transcripts in $\mathrm{C} 3 \mathrm{H} / \mathrm{HeJ}$ mouse splenocytes were higher than that in splenocytes from $\mathrm{C} 3 \mathrm{H} / \mathrm{HeN}$ mouse (Fig. 2B). However, little BAFF transcripts in $\mathrm{C} 3 \mathrm{H} / \mathrm{HeN}$ sprenocytes were detected in the culture with $1 \%$ FBS. It may be due to cell damage, which was resulted from the massive production of ROS in the culture with $1 \%$ FBS. ROS were produced by serum deprivation in both types of sprenocytes from $\mathrm{C} 3 \mathrm{H} / \mathrm{HeN}$ and $\mathrm{C} 3 \mathrm{H} / \mathrm{HeJ}$ mice (Fig. 3A). When the percentage of FBS was reduced in the culture, wildtype $\mathrm{C} 3 \mathrm{H} / \mathrm{HeN}$ TLR4 functional cells produce more ROS than $\mathrm{C} 3 \mathrm{H} / \mathrm{HeJ}$ TLR4 non-functional cells do (Fig. 3A). So, it demonstrates that wildtype $\mathrm{C} 3 \mathrm{H} / \mathrm{HeN}$ TLR4 functional cells could be more damaged by ROS than TLR4 non-functional cells in the culture with $1 \%$ FBS.

ROS-induced BAFF expression was confirmed by the treatment with $\mathrm{N}$-acetylcysteine (NAC), a well-known ROS scavenger (Fig. 3B). TLR4-independent ROS-induced BAFF expression was re-affirmed by the treatment of splenocytes with $\mathrm{H}_{2} \mathrm{O}_{2}$ (Fig. 4). It suggests that ROS might increase BAFF transcripts independent of TLR4 functionality.

\section{ROS-mediated BAFF expression was MyD88-independent}

Given that MyD88, adaptor proteins could be recruited to TLR and lead to the activation of NF-кB (Muzio et al., 1997; Wesche et al., 1997), we investigated whether BAFF expression could be independent of MyD88 or not. Previous report showed that BAFF expression was mediated by the activation of NF-кB (Fu et al., 2006; Moon et al., 2006; Tai et al., 2006). Here, we compared BAFF expression in splenocytes from wildtype and MyD88 ${ }^{-1-}$ mice. Intracellular ROS amounts in wildtype mouse splenocytes were higher than that in splenocytes from MyD88 ${ }^{-I-}$ mouse (Fig. 5A). BAFF transcripts were increased by the incubation with $3 \%$ FBS compared to $10 \%$ FBS in wildtype and MyD88 $8^{-1-}$ mouse splenocytes. When both types of splenocytes were cultured with $3 \%$ FBS, BAFF transcripts were much higher in wildtype mouse splenocytes than that in splenocytes from MyD88 ${ }^{-1-}$ mouse (Fig. 5B). However, ROS were produced by serum deprivation in both types of splenocytes from wildtype and MyD88 ${ }^{-1-}$ mouse (Fig. 5C). MyD88-independent ROS-induced BAFF expression was confirmed by the treatment of splenocytes with $\mathrm{H}_{2} \mathrm{O}_{2}$ (Fig. $6)$. It suggests that ROS might increase BAFF transcripts independent of the existence of MyD88 gene. 
A.
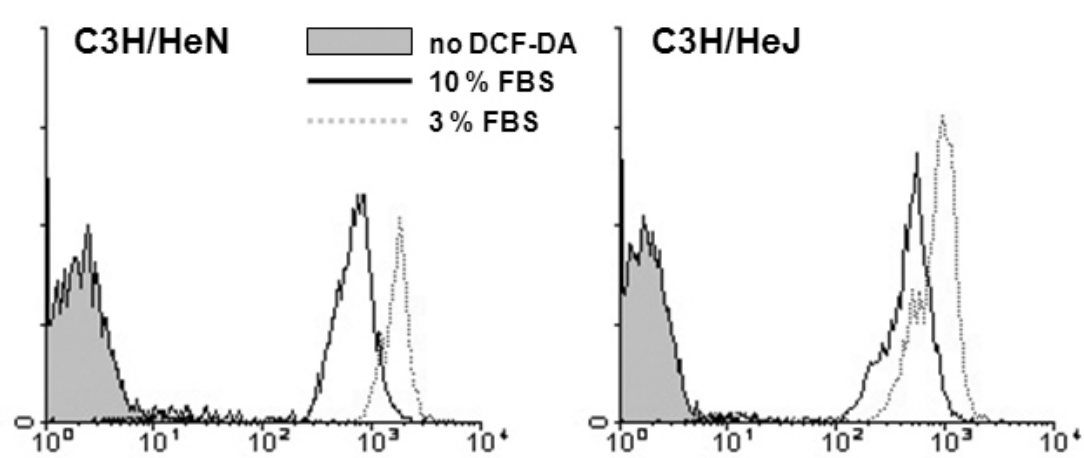

B.

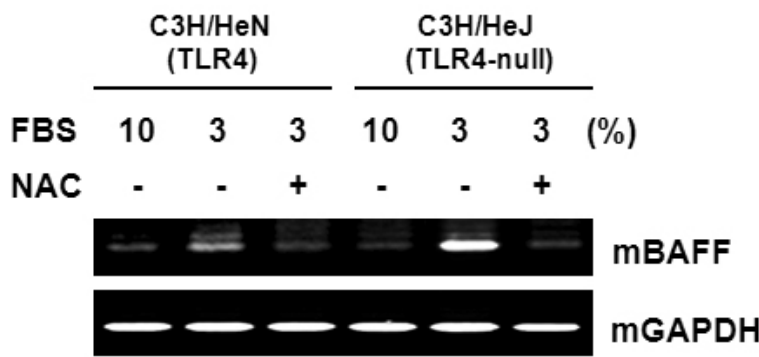

Fig. 3. BAFF transcripts dependent on ROS production. (A) Splenocytes from $\mathrm{C} 3 \mathrm{H} / \mathrm{HeN}$ TLR4-functional and C3H/HeJ TLR4-nonfunctional mice were prepared and cultured in the presence of 3 and 10\% FBS. ROS production was measured by the incubation with DCF-DA. 10,000 ROS-positive cells were analyzed by flow cytometry. (B) Splenocytes were cultured with 3 and $10 \%$ FBS in the presence or absence of $\mathrm{N}$-acetylcysteine (NAC), well-known ROS scavenger. BAFF transcripts were detected by RTPCR.

\section{$\mathrm{H}_{2} \mathrm{O}_{2}(50 \mu \mathrm{M})$}

$\begin{array}{llllll}0 & 0.25 & 0.5 & 1 & 2 & 3\end{array}$
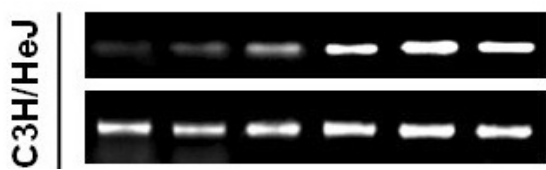

(h)

mBAFF

mGAPDH

Fig. 4. $\mathrm{H}_{2} \mathrm{O}_{2}$-induced BAFF expression in $\mathrm{C} 3 \mathrm{H} / \mathrm{HeJ}$ TLR4nonfunctional mouse splenocytes. Splenocytes from $\mathrm{C} 3 \mathrm{H} / \mathrm{HeJ}$ mice were prepared and cultured in the presence of $50 \mu \mathrm{M} \mathrm{H}_{2} \mathrm{O}_{2}$ for various times. BAFF transcripts were detected by RT- PCR.

\section{DISCUSSION}

BAFF expression in splenocytes was regulated by ROSproducing conditions such as TLR4 agonist, LPS-stimulation, serum-deprivation and ROS-scavenging enzyme, Prx II deletion (Moon et al., 2006). Little is known about the regulation of ROS-mediated BAFF expression by TLR4 functionality and the existence of MyD88 gene. Here, we investigated the role of TLR4 and MyD88 on ROS-mediated expression of BAFF using $\mathrm{C} 3 \mathrm{H} / \mathrm{HeJ}$, TLR4 non-functional mice and MyD88-deficient mice. We found that serum deprivation increased BAFF transcript expression while decreasing MyD88 transcripts or TLR4 protein (Fig. 1D and E). It implicates that BAFF expression could be de- pendent on ROS production by serum deprivation. We also found that BAFF expression was more strongly increased in $\mathrm{C} 3 \mathrm{H} / \mathrm{HeJ}$, TLR4 non-functional mice and ${\mathrm{MyD} 88^{-1-}}$ splenocytes than wild type ones. (Fig. 2B and 5B). It implicates that BAFF expression could be independent of TLR4 functionality and MyD88 gene expression. It suggests that ROS are required for BAFF expression but TLR4 protein or MyD88 gene may not be crucial in BAFF expression.

Toll-like receptor 4 agonist, LPS induced ROS generation and ROS are involved in TLR4-associated activation of NF-kB (Sanlioglu et al., 2001; Asehnoune et al., 2004). Usually, ROS production was accompanied in many human diseases, which may be resulted in the changes of various gene expressions (Mates et al., 1999; Choi et al., 2005). Among them, BAFF expression was increased by LPS-stimulation though ROS production (Moon et al., 2006). Data on serum deprivation-induced reciprocal expression of BAFF to TLR4 protein was consistent to our previous report that TLR4 proteins were decreased by Prx II deletion showing the increased ROS production. In OVA-induced asthmatic mice, BAFF expression increased in surrounding bronchi was higher in Prx II ${ }^{-1-}$ mice than wild type mice (Moon et al., 2008). Wild type and TLR4-deficient mice had similar responses to allergen for short periods (Hollingsworth et al., 2006). In ad- 
A.

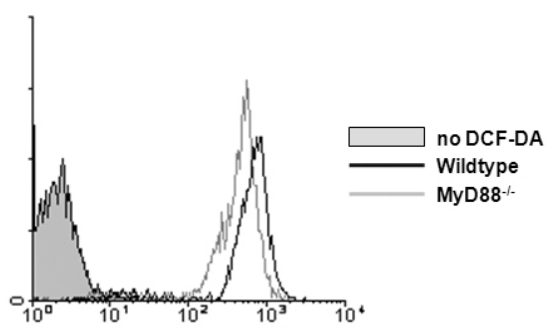

B.

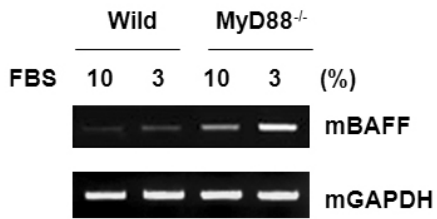

C.
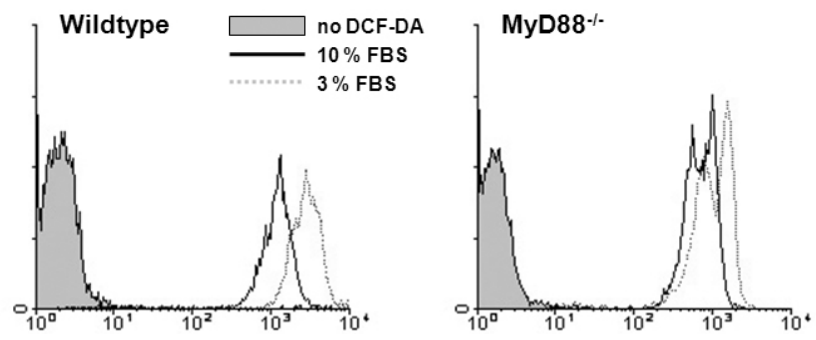

Fig. 5. MyD88-independent BAFF expression in splenocytes. (A) Splenocytes from C57BL6 wildtype and MyD88 ${ }^{-1-}$ mice were prepared. Intracellular ROS amounts were was measured by the incubation with DCF-DA. 10,000 ROS-positive cells were analyzed by flow cytometry. (B) Splenocytes were cultured in the presence of 3 and $10 \%$ FBS. BAFF transcripts were detected by RT- PCR. (C) Splenocytes from C57BL6 wildtype and ${\mathrm{MyD} 88^{-1-}}$ mice were prepared and cultured in the presence of 3 and $10 \%$ FBS. ROS production was measured by the incubation with DCF-DA. 10,000 ROS-positive cells were analyzed by flow cytometry.

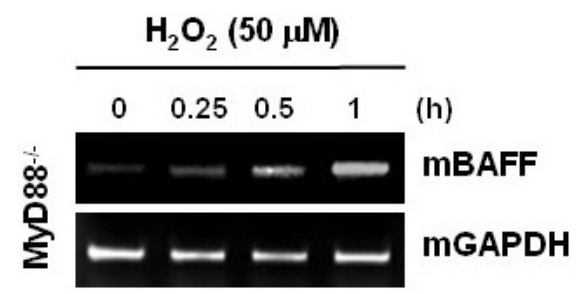

Fig. 6. $\mathrm{H}_{2} \mathrm{O}_{2}$-induced BAFF expression in MyD88 ${ }^{-1-}$ mouse splenocytes. Splenocytes from $\mathrm{C} 3 \mathrm{H} / \mathrm{HeJ}$ mice were prepared and cultured in the presence of $50 \mu \mathrm{M} \mathrm{H}_{2} \mathrm{O}_{2}$ for various times. BAFF transcripts were detected by RT- PCR.

dition, MyD88 expression was decreased by serum deprivation and serum deprivation-induced BAFF expression was increased by the deletion of MyD88 gene. Our results suggest that ROS-mediated genes could differentially affect the other genes, positively or negatively.

Serum deprivation-induced ROS production could contribute to BAFF, MyD88 and TLR4 expression by the regulation of other target genes or proteins. Transcriptional regulation is a priority candidate to serum deprivation-induced gene expression. ROS activate NF- $\mathrm{KB}$ (Toledano and Leonard, 1991; Baeuerle and Henkel, 1994; Zhang et al., 1994; Flohe et al., 1997; Asehnoune et al., 2004). ROS and other free radicals can also activate AP-1 and NF- $\mathrm{KB}$ transcription coordinately (Dhar et al., 2002). Co-activator, p300 could be involved in transcriptional regulation of ROS-mediated gene expression (Janknecht and Hunter, 1996; Janknecht and Hunter, 1996; Gerritsen et al., 1997; Perkins et al., 1997)

In conclusion, ROS produced by serum deprivation augment BAFF gene expression and inhibit MyD88 gene expression and TLR4 protein production. This implicates that BAFF expression may not require TLR4 and MyD88 expression in our experimental condition. It suggests that BAFF, MyD88 and TLR4 expressions are differentially regulated by ROS and affect each other, differentially.

\section{ACKNOWLEDGMENTS}

This work was supported by the Korea Research Foundation Grant funded by the Korean Government (MOEHRD, Basic Research Promotion Fund) (KRF-2008331-C00218).

\section{REFERENCES}

Adachi, O., Kawai, T., Takeda, K., Matsumoto, M., Tsutsui, H., Sakagami, M., Nakanishi, K. and Akira, S. (1998). Targeted disruption of the MyD88 gene results in loss of IL-1- and IL-18-mediated function. Immunity 9, 143-150.

Akira, S., Yamamoto, M. and Takeda, K. (2003). Role of adapters in Toll-like receptor signaling. Biochem. Soc. Trans. 31, 637-642.

Asehnoune, K., Strassheim, D., Mitra, S., Kim, J. Y. and Abraham, E. (2004). Involvement of reactive oxygen species in Toll-like receptor 4-dependent activation of NF-kappa B. J. Immunol. 172, 2522-2529.

Baeuerle, P. A. and Henkel, T. (1994). Function and activation of NF-kappa B in the immune system. Annu. Rev. Immunol. 12, 141-179.

Choi, M. H., Lee, I. K., Kim, G. W., Kim, B. U., Han, Y. H., Yu, D. Y., Park, H. S., Kim, K. Y., Lee, J. S., Choi, C., Bae, Y. S., Lee, B. I., Rhee, S. G. and Kang, S. W. (2005). Regulation of PDGF signalling and vascular remodelling by peroxiredoxin II. Nature. 435, 347-353.

Corrigan, C. (2004). Mechanisms of intrinsic asthma. Curr. Opin. Allergy Clin. Immunol. 4, 53-56.

Dhar, A., Young, M. R. and Colburn, N. H. (2002). The role of 
AP-1, NF-kappaB and ROS/NOS in skin carcinogenesis: the JB6 model is predictive. Mol. Cell Biochem. 234-235, 185193.

Flohe, L., Brigelius-Flohe, R., Saliou, C., Traber, M. G. and Packer, L. (1997). Redox regulation of NF-kappa B activation. Free Radic. Biol. Med. 22, 1115-1126.

Fu, L., Lin-Lee, Y. C., Pham, L. V., Tamayo, A., Yoshimura, L. and Ford, R. J. (2006). Constitutive NF-kappaB and NFAT activation leads to stimulation of the BLyS survival pathway in aggressive B-cell lymphomas. Blood 107, 4540-4548.

Gerritsen, M. E., Williams, A. J., Neish, A. S., Moore, S., Shi, Y. and Collins, T. (1997). CREB-binding protein/p300 are transcriptional coactivators of p65. Proc. Natl. Acad. Sci. USA. 94, 2927-2932.

Han, Y. H., Kim, H. S., Kim, J. M., Kim, S. K., Yu, D. Y. and Moon, E. Y. (2005). Inhibitory role of peroxiredoxin II (Prx II) on cellular senescence. FEBS Lett. 579, 4897-4902.

Han, Y. H., Kwon, J. H., Yu, D. Y. and Moon, E. Y. (2006). Inhibitory effect of peroxiredoxin II (Prx II) on Ras-ERK-NFkappaB pathway in mouse embryonic fibroblast (MEF) senescence. Free Radic. Res. 40, 1182-1189.

Hollingsworth, J. W., Whitehead, G. S., Lin, K. L., Nakano, H., Gunn, M. D., Schwartz, D. A. and Cook, D. N. (2006). TLR4 signaling attenuates ongoing allergic inflammation. $J$. Immunol. 176, 5856-5862.

Hultmark, D. (1994). Macrophage differentiation marker MyD88 is a member of the Toll/IL-1 receptor family. Biochem. Biophys. Res. Commun. 199, 144-146.

Janknecht, R. and Hunter, T. (1996). Transcription. A growing coactivator network. Nature 383, 22-23.

Janknecht, R. and Hunter, T. (1996). Versatile molecular glue. Transcriptional control. Curr. Biol. 6, 951-954.

Litinskiy, M. B., Nardelli, B., Hilbert, D. M., He, B., Schaffer, A., Casali, P. and Cerutti, A. (2002). DCs induce CD40-independent immunoglobulin class switching through BLyS and APRIL. Nat. Immunol. 3, 822-829.

Lord, K. A., Hoffman-Liebermann, B. and Liebermann, D. A. (1990). Nucleotide sequence and expression of a cDNA encoding MyD88, a novel myeloid differentiation primary response gene induced by IL6. Oncogene 5, 1095-1097.

Mackay, F., Schneider, P., Rennert, P. and Browning, J. (2003). Baff and april: a tutorial on B cell survival. Annu. Rev. Immunol. 21, 231-264.

Mackay, F., Woodcock, S. A., Lawton, P., Ambrose, C., Baetscher, M., Schneider, P., Tschopp, J. and Browning, J. L. (1999). Mice transgenic for BAFF develop lymphocytic disorders along with autoimmune manifestations. J. Exp. Med. 190, 1697-1710.

Mates, J. M., Perez-Gomez, C. and Nunez de Castro, I. (1999). Antioxidant enzymes and human diseases. Clin. Biochem. 32, 595-603.

Moon, E. Y. (2008). Serum deprivation enhances apoptotic cell death by increasing mitochondrial enzyme activity. Biomol. Ther. 16, 1-8.

Moon, E. Y., Han, Y. H., Lee, D. S., Han, Y. M. and Yu, D. Y. (2004). Reactive oxygen species induced by the deletion of peroxiredoxin II (Prxll) increases the number of thymocytes resulting in the enlargement of Prxll-null thymus. Eur. J. Immunol. 34, 2119-2128.

Moon, E. Y., Kang, J. S., Han, S. H., Yang, K. H., Pyo, S., Lee, M. Y., Lee, H. K. and Yu, D. Y. (2008). Differential role of peroxiredoxin II (PrxlI) on the expression of toll-like receptor 4 (TLR4) and B-cell activating factor (BAFF) in ovalbumin (OVA)-induced mouse asthma. Int. Immunopharmacol. 8, 935-944.

Moon, E. Y., Lee, J. H., Oh, S. Y., Ryu, S. K., Kim, H. M., Kwak, H. S. and Yoon, W. K. (2006). Reactive oxygen species augment B-cell-activating factor expression. Free Radic. Biol. Med. 40, 2103-2111.

Muzio, M., Ni, J., Feng, P. and Dixit, V. M. (1997). IRAK (Pelle) family member IRAK-2 and MyD88 as proximal mediators of IL-1 signaling. Science 278, 1612-1615.

Ostergaard, P. A. (1985). Non-lgE-mediated asthma in children. Acta. Paediatr. Scand. 74, 713-719.

Perkins, N. D., Felzien, L. K., Betts, J. C., Leung, K., Beach, D. H. and Nabel, G. J. (1997). Regulation of NF-kappaB by cyclin-dependent kinases associated with the p300 coactivator. Science 275, 523-527.

Rackeman, F. M. (1947). A working classification of asthma. Am. J. Med. 33, 601-606.

Sanlioglu, S., Williams, C. M., Samavati, L., Butler, N. S., Wang G., McCray, P. B. Jr., Ritchie, T. C., Hunninghake, G. W. Zandi, E. and Engelhardt, J. F. (2001). Lipopolysaccharide induces Rac1-dependent reactive oxygen species formation and coordinates tumor necrosis factor-alpha secretion through IKK regulation of NF-kappa B. J. Biol. Chem. 276 , 30188-30198.

Schiemann, B., Gommerman, J. L., Vora, K., Cachero, T. G. Shulga-Morskaya, S., Dobles, M., Frew, E. and Scott, M. L. (2001). An essential role for BAFF in the normal development of B cells through a BCMA-independent pathway. Science 293, 2111-2114.

Schneider, P., MacKay, F., Steiner, V., Hofmann, K., Bodmer, J. L., Holler, N., Ambrose, C., Lawton, P., Bixler, S., AchaOrbea, H., Valmori, D., Romero, P., Werner-Favre, C., Zubler, R. H., Browning, J. L. and Tschopp, J. (1999). BAFF, a novel ligand of the tumor necrosis factor family, stimulates $B$ cell growth. J. Exp. Med. 189, 1747-1756.

Tai, Y. T., Li, X. F., Breitkreutz, I., Song, W., Neri, P., Catley, L., Podar, K., Hideshima, T., Chauhan, D., Raje, N., Schlossman, R., Richardson, P., Munshi, N. C. and Anderson, K. C. (2006). Role of B-cell-activating factor in adhesion and growth of human multiple myeloma cells in the bone marrow microenvironment. Cancer Res. 66, 6675-6682.

Toledano, M. B. and Leonard, W. J. (1991). Modulation of transcription factor NF-kappa B binding activity by oxidationreduction in vitro. Proc. Natl. Acad. Sci. USA. 88, 4328-4332.

Wesche, H., Henzel, W. J., Shillinglaw, W., Li, S. and Cao, Z. (1997). MyD88: an adapter that recruits IRAK to the IL-1 receptor complex. Immunity 7, 837-847.

Zhang, H., Spapen, H., Nguyen, D. N., Benlabed, M., Buurman, W. A. and Vincent, J. L. (1994). Protective effects of $\mathrm{N}$-acetyl-L-cysteine in endotoxemia. Am. J. Physiol. 266, $\mathrm{H} 1746-1754$. 